\title{
QUEEN'S
QNEIVERSITY
BELFAST
}

\section{Organic composition and multiphase stable isotope analysis of active, degrading and restored blanket bog}

McAnallen, L., Doherty, R., \& Ogle, N. (2017). Organic composition and multiphase stable isotope analysis of active, degrading and restored blanket bog. Science of the Total Environment, 599-600, 1779-1790.

https://doi.org/10.1016/j.scitotenv.2017.05.064

Published in:

Science of the Total Environment

Document Version:

Peer reviewed version

Queen's University Belfast - Research Portal:

Link to publication record in Queen's University Belfast Research Portal

Publisher rights

(c) 2017 Elsevier. This manuscript is distributed under a Creative Commons Attribution-NonCommercial-NoDerivs License

(https://creativecommons.org/licenses/by-nc-nd/4.0/), which permits distribution and reproduction for non-commercial purposes, provided the author and source are cited

\section{General rights}

Copyright for the publications made accessible via the Queen's University Belfast Research Portal is retained by the author(s) and / or other copyright owners and it is a condition of accessing these publications that users recognise and abide by the legal requirements associated with these rights.

Take down policy

The Research Portal is Queen's institutional repository that provides access to Queen's research output. Every effort has been made to ensure that content in the Research Portal does not infringe any person's rights, or applicable UK laws. If you discover content in the Research Portal that you believe breaches copyright or violates any law, please contact openaccess@qub.ac.uk. 


\title{
Organic composition and multiphase stable isotope analysis of active, degrading and restored blanket bog
}

\author{
Laura McAnallen*, Rory Doherty, Neil Ogle \\ School of Natural and Built Environment, Queen’s University Belfast, BT9 5AG United Kingdom.
}

Correspondence to: Laura McAnallen (lmcanallen01@qub.ac.uk)

\begin{abstract}
Here we used organic composition and stable isotopic analysis to evaluate the effects of drainage and restoration at an ombrotrophic peatland, to assess whether rewetting of blanket bogs will reverse degradation. The organic composition of the peat and the isotopic fractionation between the solid (peat), liquid (pore water) and gas (soil gas) phases on actively accumulating, degrading and restored locations are compared. Fourier Transform Infrared Spectroscopy (FTIR) analysis of the organic material has shown a high level of humification (low decomposition) in the active peat. Stable isotope analysis in the solid, liquid and gas phases has corresponded with this and indicated that the active location is enriched in ${ }^{13} \mathrm{C}$ in the solid and gas phases, ${ }^{15} \mathrm{~N}$ in the solid phase, ${ }^{18} \mathrm{O}$ in the liquid and gas phases and $\mathrm{D}$ in the liquid phase, suggesting a closed system with limited isotopic fractionation and thus limited water movement and decomposition. The degrading location has a lower level of humification, and is depleted in ${ }^{13} \mathrm{C}$ in the solid phase due to ingression of vascular plants. The restored location has high humification and enrichment of ${ }^{13} \mathrm{C}$ and ${ }^{15} \mathrm{~N}$ in the solid phase, and $\mathrm{D}$ in the liquid phase suggesting increased microbial activity. ${ }^{13} \mathrm{C}$ and ${ }^{18} \mathrm{O}$ in the gas phase and ${ }^{18} \mathrm{O}$ in the liquid phase are depleted, as a result of microbial mediated gas production and rewetting. FTIR analysis has also indicated a subsurface zone of increased decomposition between the acrotelm and catotelm in both the active and degrading peat. This is due to a stable water table and is not present within the restored location, which we attribute to water table fluctuation associated with rewetting. This zone of increased decomposition adds to the complexity of blanket bog peatlands and the assumption that all systems can be generalized under one conceptual model.
\end{abstract}


Key words: peatland, restoration, humification, Fourier Transform Infrared Spectroscopy (FTIR), redox boundary, mesotelm.

\section{Highlights:}

- $\quad$ Isotope fractionation between active, degraded and restored peat is somewhat cyclic

- Degradation results in decreased humification

- Ingression of vascular plants in the degraded area depletes ${ }^{13} \mathrm{C}$ in the solid phase

- $\quad$ Restoration processes by rewetting partially reverses degradation

\section{Introduction}

Peatlands cover an area of around 4 million $\mathrm{km}^{2}$ or $3 \%$ of the world's land area (Bain et al. 2011), however this figure is declining due to agricultural intensification over the last 200 years (Walter et al. 2015). The European Union (EU) Habitats Directive describes peatlands as significant global carbon stores that also provide important ecosystem services, such as atmospheric pollutant interception and storage as well as flood prevention (Tinch 2009). Water derived from active blanket bogs is naturally of a high quality, as being ombrotrophic, they intercept and retain various atmospheric pollutants (Committee on Climate Change 2013). Organic soils develop under conditions of excess water and are known to be porous and hold a large amount of water when saturated (Boelter 1966). The water (and atmospheric pollutants) stored in the peat, is flow regulated, meaning it is held and maintained, mitigating any local droughts or flooding (Parish et al. 2008). Globally, efforts are now being made to protect and restore peatlands due to the realization of their potential as significant global carbon sinks, habitats of rare flora and fauna and as important water catchments.

Peatlands are commonly conceptualized by one diplotelmic model, referred to as the acrotelm and catotelm (Ingram 1978). The acrotelm is postulated by Ingram (1978) as the upper layer of peat where water table fluctuations occur (oxygenated peat horizon) due to the high porosity and high hydraulic conductivity (Biester et al. 2005). This zone is characterized by a high organic matter content that is comprised of plant roots and decomposing plant material (Evans et al. 1999). It is thought that the highest rates of decomposition occur in the acrotelm and result in $\mathrm{CO}_{2}$ efflux into the atmosphere (Thormann 2006). It is also commonly accepted that the catotelm is permanently waterlogged and characterized by anoxic conditions and slow decomposition (Biester et al. 2014). This conceptualization is highly generalized and may not be representative of all peatland 
types. The diplotelmic model by Ingram (1978) generally accounts for peat hydrology and more specifically, water table levels. In reality however, peatlands are highly complex and are characterized by a number of factors, such as temperature, vegetation, topography, rainfall and nutrient availability. It is also known that peatland characteristics change not only with depth, but laterally (Morris et al. 2011). It is therefore almost impossible to assume one model for global peats but rather a conceptual model of decomposition processes for each site.

It is well understood that water table decline within the peat profile increases rates of organic matter decomposition (Estop-Aragonés et al. 2013). It is thought that water table drawdown into the anoxic environment introduces oxygen, causing an increase in rates of aerobic decomposition and subsequent increase and decrease in $\mathrm{CO}_{2}$ and $\mathrm{CH}_{4}$ flux respectively (Lai 2009). More recent research undertaken by Estop-aragonés \& Blodau (2012) have found that within some sites, this is true and that relative to saturated conditions, $\mathrm{CO}_{2}$ production increases with drying, however only up until an optimum moisture content, and then decreases with further drying. This further emphasizes the variability amongst peatland types. Although peatland areas are now being protected and restored due to their recognition as an endangered form of habitat biodiversity, little research has been undertaken regarding the effects of re-wetting of drained peatlands on rates of decomposition and gas efflux. Bonnett et al. (2009) argued that ideally monitoring prior to restoration is needed to provide a pre-restoration baseline, or by comparing results to a control or reference site from which comparisons can be made. In reality such a location where monitoring has been undertaken prior to restoration, or locating a site of similar characteristics (vegetation, topography, rainfall, temperature or elevation) is difficult to find.

With these benefits of protection and restoration in mind, in this study we compared the quality and composition of organic material between: a drained and over grazed (degrading) peat; an actively accumulating peat (active); and a previously drained and overgrazed peat which has undergone drain blocking and reduced grazing (restored) from an upland blanket bog catchment in Northern Ireland. Various methods, such as Fourier Transform Infrared Spectroscopy (FTIR) and Stable Isotope Analysis were used to compare solid, liquid and gas phases within each of the three locations to determine the effects of raising of the water table post drainage. 


\section{Material and Methods}

\subsection{The Study Site}

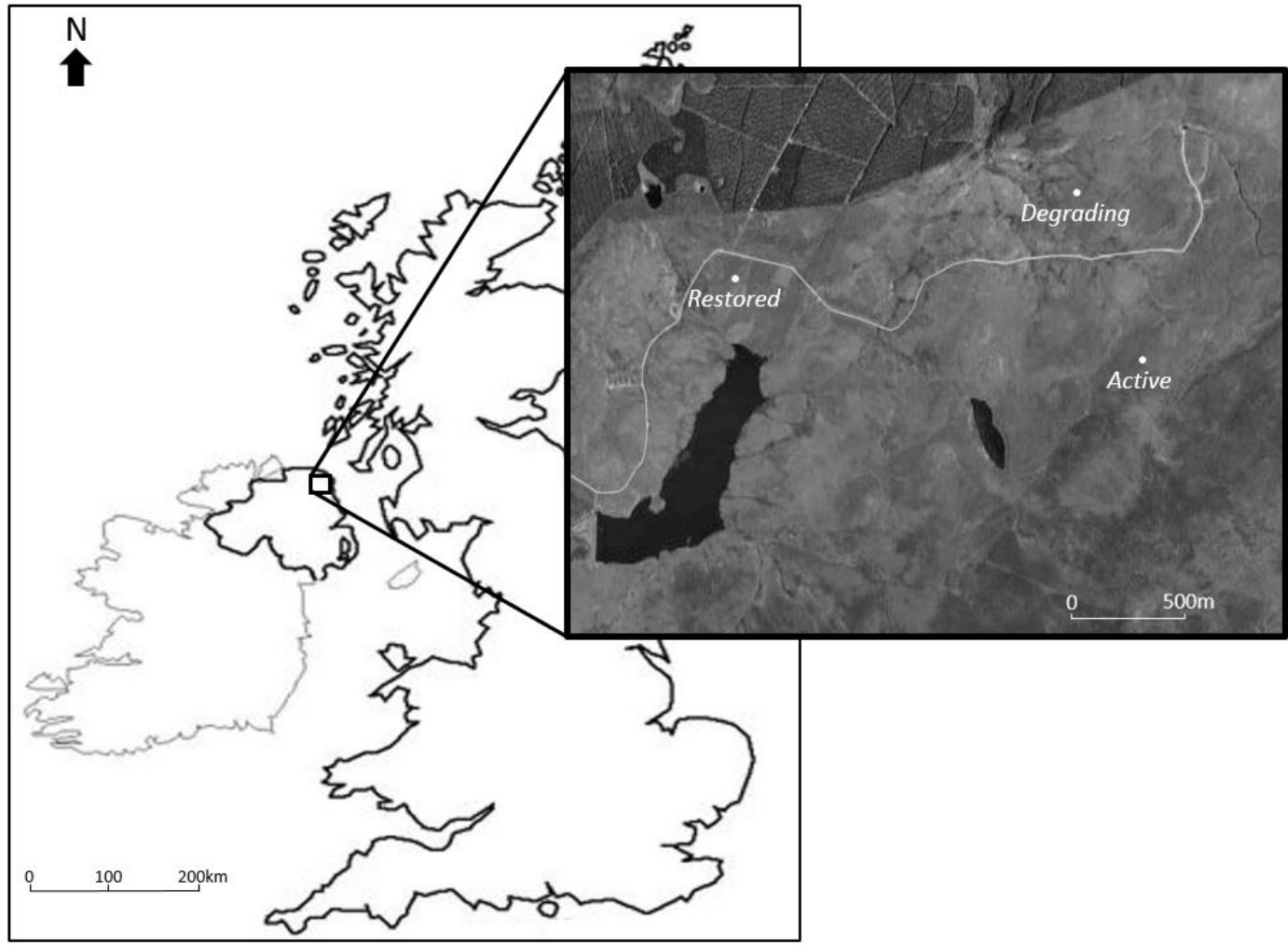

Fig. 1. Location of the Garron Plateau within the United Kingdom

The Garron Plateau (Fig. 1) (latitude 55.003, longitude -6.061) blanket bog in Northern Ireland encompasses an area of over 4,650 ha (Joint Nature Conservation Committee, 2010). The peatland complex is a designated Area of Special Scientific Interest (ASSI), Special Area of Conservation (SAC), Special Protection Area (SPA) and a Ramsar site. A previous condition assessment undertaken by the Department of Agriculture, Environment and Rural Affairs (DAERA) in 2010, determined some areas to be in unfavourable condition. This condition assessment involved a visual inspection of the site using a combination of aerial photography (for drains, erosion gullies or land susceptible to erosion), estimation of plant cover in $2 \mathrm{x} 2 \mathrm{~m}$ plots and condition assessment structured walks (McKeown \& Corbett 2015). Degradation at the site is predominantly a result of financial incentives by the government in the 60's and 70's to drain peatland areas for agricultural purposes and the subsequent high volume of sheep grazing on the land. Following this assessment, over 2,000ha of the lessdegraded and damaged areas have since been re-wetted in an attempt to restore the peat back to health. This was 
completed in April 2014, and entailed blocking drains in order to raise the water table and also reducing and restricting the volume of sheep grazing at the site (Department of the Environment for Northern Ireland 2003).

\subsection{Field Sampling}

Using the knowledge gained from the condition assessment undertaken in 2010, an area was chosen from within each of the three locations (degrading, active and restored) previously defined by DAERA. The Garron Plateau was chosen for this study as it is such an expansive site, containing degrading, active and restored locations, which ensured each area was under similar environmental conditions (i.e. rainfall and temperature), which could affect vegetation growth, microbe activity, moisture levels and nutrient availability. Using the previous condition assessment undertaken by DAERA, RSPB reported the estimated area of the degrading, active and restored locations to be approximately 289.76, 1005.79 and 633.39 ha, respectively (Burns 2011). Using the geographical coordinates from the central sample location within each grid, the distance between the restored and active areas was calculated to be approximately 1.26 miles, the restored and degrading as 1.06 miles and the degrading and active as 0.52 miles. In addition, the degrading area is isolated by a small road through the site and the active area is located at a higher elevation. It has therefore been acknowledged that although each area is located on one site, the distance between each of the locations are large enough to determine them as independent from each other.

Solid peat samples were taken for FTIR and Stable Isotope Analysis following British Geological Survey G-BASE sampling protocol (Johnson 2005). This involved using a $20 \mathrm{~m}$ x $20 \mathrm{~m}$ square grid and taking a peat sample from each corner and also the centre of the grid (giving 5 sample points) from each of the three areas (Degrading (D) 1-5, active (A) 1-5 and restored (R) 1-5). (The location of the sampling grid within each area was chosen based on accessibility and ease of access for transporting equipment and samples). As the location of the water table in relation to the peat surface is an important factor in the biogeochemical processes that occur in the peat, samples were also taken at depths of 5, 15, 25 and $35 \mathrm{~cm}$ below ground level (giving 20 samples from each area (60 in total)). Where averages were taken (Fig. 2, 4b, 5, and 6), these were calculated from the mean values of each of the five sample locations within each area. Although previous work at the site has found that the maximum peat thickness at the site is approximately $3 \mathrm{~m}$, the near subsurface, and zone of acrotelm to catotelm differentiation was chosen. A depth of $35 \mathrm{~cm}$ was chosen as in a typical year it is known that in general, a peatland water table fluctuates within the top $30 \mathrm{~cm}$ of the peat (Shi et al. 2015). It was also 
recognised by Esmeijer-Liu et al. (2012) that the top 0 to $\pm 10 \mathrm{~cm}$ contain the youngest peat which is under aerobic conditions and from $20+\mathrm{cm}$ is where stability of the catotelm begins. The zone in between $(10-20 \mathrm{~cm})$ is where water table fluctuation and catotelm immobilisation is thought to occur (Esmeijer-Liu et al. 2012). The solid samples were collected using a Russian style peat auger which was inserted vertically into the peat layer at each sample location and placed into air-tight sealed sample bags.

In addition, pore water samples were collected from each sample location (1-5) within the three areas (degrading, active and restored) using a peristaltic pump and placed into amber glass bottles from the same locations, post core collection for isotopic analysis. The pore water samples were collected approximately one hour after core collection to minimise the effects of the disturbance and to allow the water table to settle. All samples were taken back to the lab in low temperature (approx. $4^{\circ} \mathrm{C}$ ) cooler boxes.

Soil gas samples were also collected for stable isotope analysis of carbon and oxygen using a closed static chamber method (Zerva 2004) at each of the sample locations (1-5) within the three areas (degrading, active and restored). Gas sample collection was performed the week prior to solid and liquid sampling to minimise the effects of peat subsurface disturbance. Two of the most widely used techniques for the collection of gas samples are from closed dynamic chambers and closed static chambers, with the difference between the two being the absence of air circulation (Zerva 2004). As closed dynamic chambers involve the circulation of air directly from the chamber to the measuring equipment and it was impractical to transport equipment onsite, the closed static chamber method was employed. The sampling procedure involved using a heavy closed chamber with a volume of $5.03 \mathrm{~L}$ which was placed tightly onto the peat to ensure no atmospheric air would enter into the chamber. The chamber was pumped until it was a vacuum and then allowed to accumulate for 30 minutes before a pump was used to collect gas samples into 0.6 L Tedlar bags. The gas samples were taken back to the lab for stable carbon and oxygen isotopic analysis of carbon dioxide $\left(\mathrm{CO}_{2}\right)$ within 24 hours to ensure no leakage or contamination from the atmosphere.

\subsection{Analytical Procedures}

\subsubsection{FTIR Spectroscopy}

The solid peat samples were air-dried in the oven at a constant temperature of $28{ }^{\circ} \mathrm{C}$ until a constant mass was achieved. The samples were then milled to a fine powder using a SPEX CertiPrep cryogenic freezer mill 6850. The dried and powdered peat from each location was then analysed using FTIR to determine the organic matter 
composition at different depths. Fourier Transform Infrared (FTIR) spectroscopy is a technique which has been widely used to characterise organic matter quality of bulk peat (Holmgren \& Norden 1988) and is capable of distinguishing the principal chemical classes in soil organic matter, such as carbohydrates, lignins, cellulose, fats and/or lipids and proteinaceous compounds, through the vibrational characteristics of their structural chemical bonds (Artz et al. 2008). The spectral characterisation of our peat samples was obtained with a Jasco FT/IR4100 at a scan range of $4000-650 \mathrm{~cm}^{-1}$ and a resolution of $4 \mathrm{~cm}^{-1}$. Each sample was analysed three times and an average taken for analytical precision. A background reading was also taken between each sample to ensure results did not deviate due to any atmospheric changes within the lab.

\subsubsection{Stable Isotope Analysis}

As FTIR is a non-destructive technique, the same peat samples were used for stable isotopic analysis of carbon and nitrogen. Isotopes of a certain element contain the same number of protons ( $\mathrm{Z}$ ) but a different number of neutrons (N) (Zeebe \& Wolf-Gladrow 2001) which gives them different molecular weights. Isotope compositions are expressed in ratios of the heavier isotope to the lighter one. All elements that form solid, liquid and gaseous compounds stable over a wide temperature range are likely to have variations in isotopic composition (Hoefs 2009). During biological reactions (e.g. photosynthesis or bacterial processes) the ratio of heavy to light isotopes changes, as the lighter isotope is more often used during the reaction, leaving the substrate enriched in the heavier isotope (Hoefs 2009). The Rayleigh distillation equation (Eq. (1)) can be used to describe this process of kinetic fractionation, whereby the rate of change in Ratio $(R)$ is given as a function of the fraction of remaining substrate $(F)$ during diminution of the substrate reservoir. $R_{f}$ and $R_{\mathfrak{i}}$ are the final and initial isotope ratios of the diminishing reservoir and $x$ is the fractionation factor (Wynn et al. 2005).

$$
R_{f}=R_{\mathrm{i}} F^{x-1}
$$

Equation (1) Rayleigh Distillation equation

Stable isotope analysis of carbon and nitrogen in the solid phase was undertaken using a Thermo Flash 1112 Elemental Analyser coupled to Thermo Scientific Delta V Isotope Ratio Mass Spectrometer (IRMS). Samples 
were calibrated against an externally calibrated leucine standard (-30.52 \%o and 10.77 \%o for carbon and nitrogen respectively). Additional QC for nitrogen was ensured by measurement of the IAEA N1 standard. Analytical precision for each standard was $<0.15 \%$ for nitrogen and $<0.05 \%$ for carbon ( $\mathrm{n}=29$ for both standards). Every seventh sample was duplicated.

Stable oxygen and hydrogen analysis in the liquid phase was undertaken using a Thermo Thermal Conversion Elemental Analyser (TCEA) coupled to the Delta V IRMS. Samples were calibrated against the international standards VSMOW2 (0 \% for both hydrogen and oxygen) and SLAP2 (-427.5 \%o for hydrogen and $-55.50 \%$ o for oxygen). Each individual sample and standard was injected from a GC-PAL autosampler via a $1.2 \mu \mathrm{L}$ syringe into the TCEA 6 times to minimise memory effects. An average of the final 4 or 5 injections were accepted as the value for the sample or standard, dependent on the memory coefficient which was calculated as $\geq 0.98$ for each sample, meaning that the analysed isotope value represents $98 \%$ of the true isotope value of the sample. This protocol is described by (van Geldern \& Barth 2012). Analytical precision was $<0.25$ $\%$ and $<1 \%$ for oxygen and hydrogen respectively.

Gas analysis was performed on a Thermo Scientific Delta Ray Isotope Ratio Infrared Spectrometer (IRIS). Both samples and reference standard were measured in triplicate and analytical precision was $<0.15 \%$ for both carbon and oxygen. The standard gas was calibrated and supplied by Thermo (Calibration Gas Bio, UN 2037) and had values of $-9.7 \%$ \% \pm .3 and $-9.2 \%$ \% \pm 0.3 for carbon and oxygen respectively. Urban (Belfast) and on-site (Garron Plateau) atmospheric samples were also taken and analysed to ensure the samples collected from the chamber were representative.

\section{Results and Discussion}

\subsection{FTIR Spectroscopy in Solid Phase}

FTIR spectroscopy can be used to identify the changes in humification with depth based on the relative abundance of recalcitrant moieties such as aliphatics or aromatics compared to labile fractions, such as carbohydrates (Cocozza et al. 2003). Using this principle, the absorption peaks most indicative of the structure of organic matter were used to calculate a 'humification index ratio' (Broder et al. 2012). This humification index ratio was calculated by comparing the peak intensity for polysaccharides $(1070 \mathrm{~cm}-1$ for degrading peat and $1040 \mathrm{~cm}-1$ for active and restored peat) with substances that are typically enriched during humification of organic material, such as aromatic and phenolic compounds $(1510 \mathrm{~cm}-1)$ and carboxylic/ carboxylate structures 
(1420 cm-1) (Holmgren \& Norden 1988). The values were calculated with depth to give an interpretation of how the humification of organic material changes through the peat profile. Peat organic matter characterization using FTIR spectroscopy involves the assignment of observed spectral characteristics. The interpretation of the peat wavelengths from the relevant literature is detailed in Table 1 below.

Table 1 General assignment of IR absorption bands

\begin{tabular}{|c|c|c|}
\hline $\begin{array}{l}\text { Wavelength } \\
\left(\mathrm{cm}^{-1}\right)\end{array}$ & Vibration & Characterisation \\
\hline 3340 & O-H stretching & $\begin{array}{l}\text { Water, alcohols and phenols; carboxyl and } \\
\text { hydroxyl groups (cellulose) }^{\mathrm{a}}\end{array}$ \\
\hline 2920 & Antisymmetric $\mathrm{CH}_{2}$ & Fats, wax and lipids ${ }^{b}$ \\
\hline 2850 & Symmetric $\mathrm{CH}_{2}$ & Fats, wax and lipids ${ }^{\mathrm{b}}$ \\
\hline 1720 & $\mathrm{C}=\mathrm{O}$ stretch of $\mathrm{COOH}$ or $\mathrm{COOR}$ & Carboxylic acids, aromatic esters ${ }^{\mathrm{a}}$ \\
\hline $1600-1650$ & $\begin{array}{l}\text { Aromatic } \mathrm{C}=\mathrm{C} \text { stretching and/or } \\
\text { asymmetric C-O stretch in COO- }\end{array}$ & $\begin{array}{l}\text { Lignin and other aromatics, or aromatic or } \\
\text { aliphatic carboxylates }^{\mathrm{a}}\end{array}$ \\
\hline 1540 & Amide II N-H and C-N in plane & Proteinaceous origin $^{\mathrm{a}}$ \\
\hline 1510 & Aromatic $\mathrm{C}=\mathrm{C}$ stretching & Lignin/phenolic backbone ${ }^{\mathrm{c}}$ \\
\hline 1420 & $\begin{array}{l}\text { Symmetric C-O stretch from COO- or } \\
\text { stretch and } \mathrm{OH} \text { deformation }(\mathrm{COOH})\end{array}$ & Carboxylic/carboxylate structures (lignin) \\
\hline $1040-1070$ & C-O stretching and O-H deformation & Polysaccharides $^{\mathrm{d}}$ \\
\hline
\end{tabular}

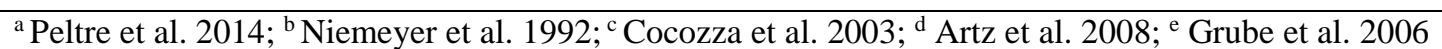




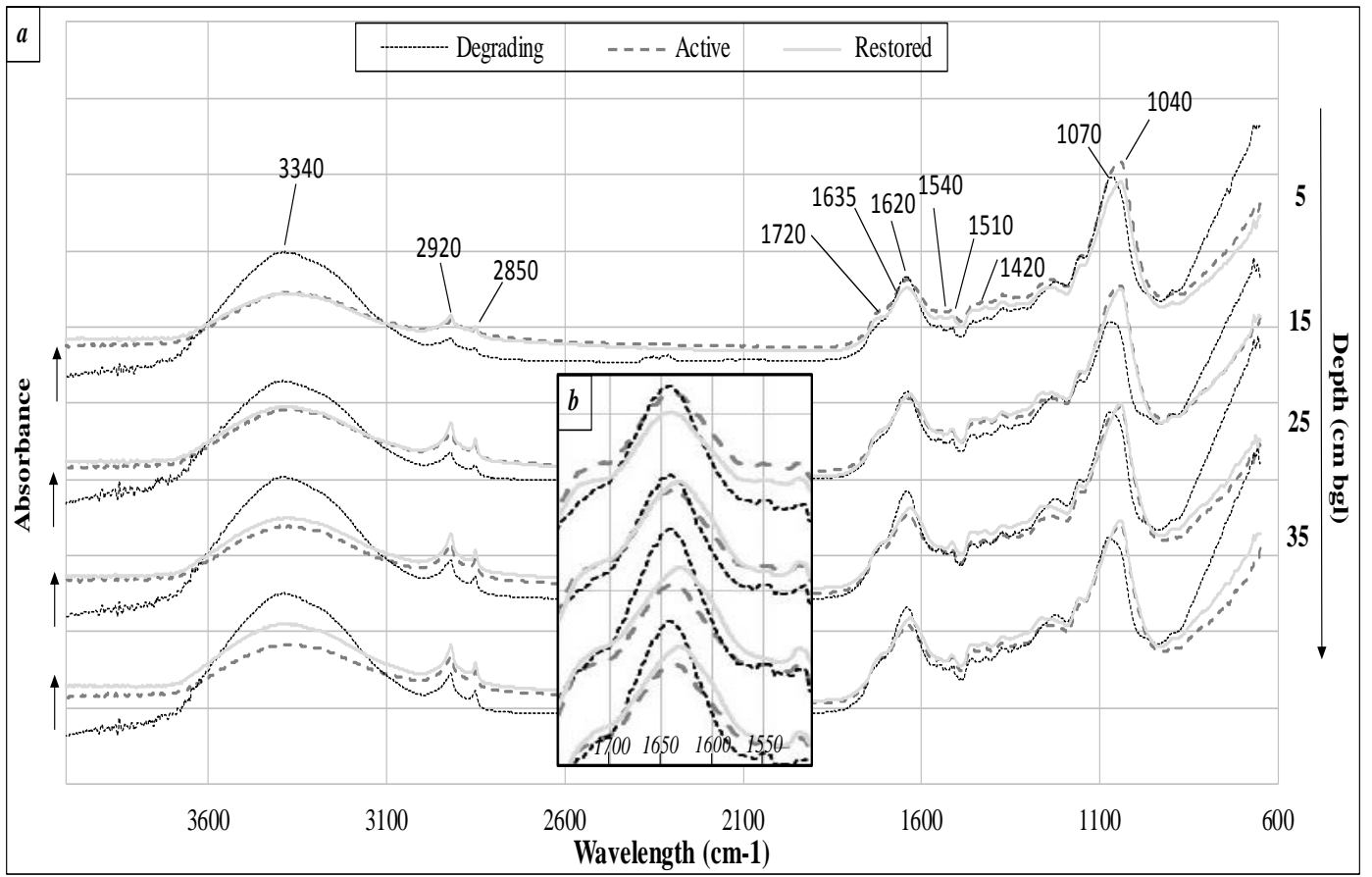

Fig. 2. Averaged raw solid spectral results calculated from the triplicate spectral values from the 5 locations to give one set of results with depth at each of the 3 areas. Close up of data from 1500$1750 \mathrm{~cm}^{-1}$. (N.B. results were off-set and overlaid only for visual clarity) (b).

The FTIR spectra in Fig. 2, pertaining to the averaged degrading, active and restored samples at depths of 5, 15, 25 and $35 \mathrm{~cm}$ show common wavelength patterns which vary in peak intensity over each area and with depth. When comparing the IR spectra with depth it can be seen from Fig. 2a that the peak intensity at $3340 \mathrm{~cm}^{-1}$ which is assigned to residual cellulose, alcohols and phenols is highest in the degrading samples. The peak intensity increases with depth in the restored samples. It can also be seen that there is a relative increase in aliphatic structures (2920 and $\left.2850 \mathrm{~cm}^{-1}\right)$ with depth and a decline in peak intensity for polysaccharides $\left(1070-1040 \mathrm{~cm}^{-}\right.$ ${ }^{1}$ ), most likely cellulose and residual hemicellulose (Artz et al. 2008), which is most apparent in the degrading samples. This is as expected as humification increases with depth (Artz et al. 2008), due to the preferential decomposition of polysaccharides under aerobic conditions, over less easily decomposable material such as aliphatic structures which are enriched with depth. It should also be noted that the wavelength peak for polysaccharides is at $1040 \mathrm{~cm}^{-1}$ for both the active and restored samples whereas it has shifted to $1070 \mathrm{~cm}^{-1}$ for the degrading samples, indicating a change in organic matter composition. The shift in peak is also seen within the spectral band from 1600-1650 $\mathrm{cm}^{-1}$ (Fig. 2b), which is indicative of carboxylates which include contributions from vibrations of aromatic and aliphatic carboxylates (R-COO-), and/or aromatic $\mathrm{C}=\mathrm{C}$ structures (Artz et al. 2008). This band range is generally more intense from the degrading samples compared to the active and restored, however more importantly, the peak wavelength for both the active and restored samples is at $1620 \mathrm{~cm}^{-}$ 
, whereas this has shifted slightly right to $1635 \mathrm{~cm}^{-1}$ for the degrading samples, further evidencing this shift in organic matter composition during degradation. This shifting in wavelength increases with depth. In general, the degrading samples have lower absorbencies (less intense peaks) at each depth, whereas the active samples have the highest absorbencies at 5 and $15 \mathrm{~cm}$, and the restored having the highest at 25 and $35 \mathrm{~cm}$.

\subsubsection{Humification Indices and Principle Component Analysis (PCA) using FTIR Data}

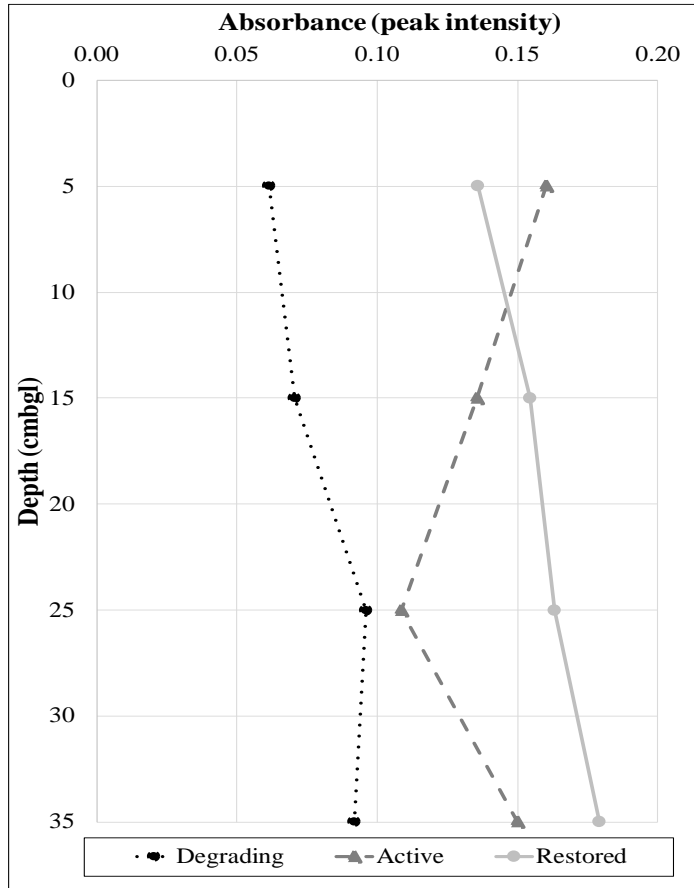

Fig. 3a. Humification index using the ratio of carboxylic/carboxylate $\left(1420 \mathrm{~cm}^{-1}\right)$ structures relative to polysaccharidic content $\left(1070 \mathrm{~cm}^{-1}\right.$ for degrading and $1040 \mathrm{~cm}^{-1}$ for active and restored). Calculated standard error was no greater than 0.00043 which occurred at $5 \mathrm{~cm}$ bgl in the restored location.

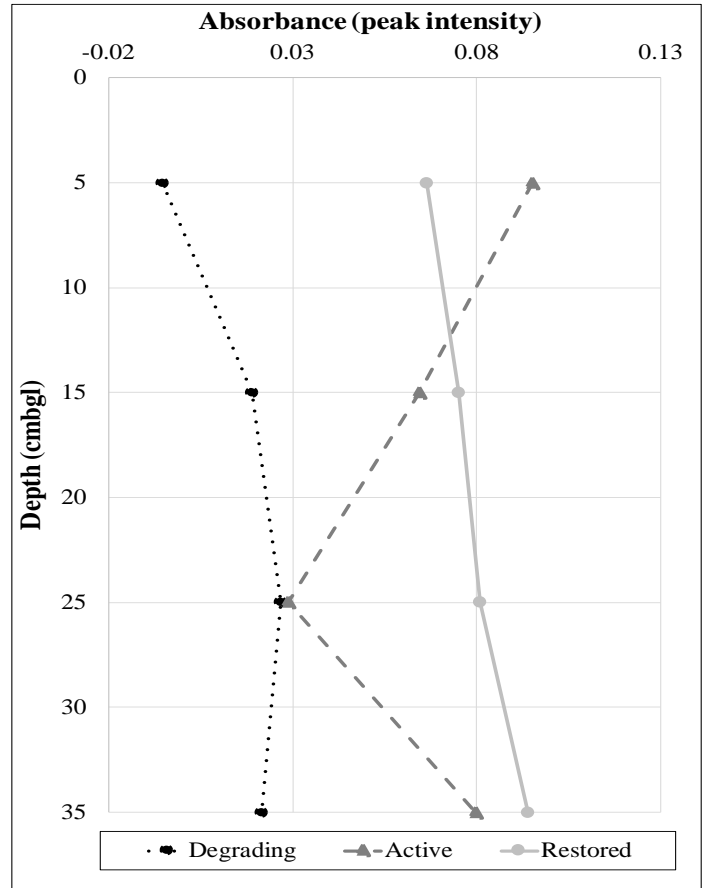

Fig. 3b. Humification index using the ratio of aromatic and phenolic compounds (1510 $\mathrm{cm}^{-1}$ ) relative to polysaccharidic content (1070 $\mathrm{cm}^{-1}$ for degrading and $1040 \mathrm{~cm}^{-1}$ for active and restored). Calculated standard error was no greater than 0.00058 which occurred at $5 \mathrm{~cm}$ bgl in the active location.

The calculation of the humification indices with depth (Figs. 3a and 3b) both indicte that humification generally increases with depth, more specifically that labile and easily decomposable polysaccharide content decreases, while aromatic, phenolic and carboxylic moieties increase with depth. The results indicate that at the surface (5 cm bgl) the active area is the most humified, with the degrading location being the least humified. The calculated values for both the active and restored areas are quite similar ( 0.14 and 0.15 respectively at $15 \mathrm{~cm}$ bgl from Fig. 3a), whereas the degrading are lower (0.08 at $15 \mathrm{~cm}$ bgl for 3a). The results suggest that humification increases almost linearly in the restored area, however the active and degrading areas both decrease in humification at 25 and $35 \mathrm{~cm}$ bgl respectively. This decrease is more prominent in the active area. This increase 
in decomposition would suggest that the conceptualised diplotelmic model by Ingram (1978) is not applicable at neither the degrading nor active sites and that the processes occurring here are more complex. A possible suggestion for this is the 'triplotelimic' model hypothesised by Clymo and Bryant (2008), whereby a third layer occurs between the acrotelm and catotelm, coined the 'mesotelm', and is the site of complicated biological and chemical processes (Clymo 2015). This layer occurs where the water table oscillates by only a few cm about its mean value and remains relatively stable. This redox boundary ('mesotelm') causes a layer where oxic and anoxic conditions are adjacent and is highly complex due to the chemical and biogeochemical processes that can be oxic, suboxic or anoxic (Yakushev \& Newton 2013). It is anticipated that water table fluctuations are minimal in the active area and occur around $25 \mathrm{~cm}$ bgl. Fig. 3 shows a slight decrease in humification at $35 \mathrm{~cm}$ bgl in the degrading area. This may also be due to the presence of a redox boundary and a similar 'mesotelm' layer, which is expected to be deeper than the active area. Although the total sample depth was only $35 \mathrm{~cm}$ bgl, the gradient is less steep than that of the active area, suggesting that the intensity of this 'spike' in decomposition is less intense. This 'mesotelm' layer is not present in the restored area, which could be a result of the water table fluctuating at such a high level that there is no evident redox boundary. This is discussed further in section 6 .

Although this humification index aids interpretation of results, as there are so many peaks, with even small changes, it is still difficult to interpret IR spectra and identify specific features and correlating them with accuracy to a specific constituent (Holmgren \& Norden 1988). Principle Component Analysis (PCA) can be used to analyse such complex datasets and is a well-known technique used for reducing the dimensionality of multivariate data whilst preserving most of the variance (Harrison et al. 2006). PCA has the ability of extracting the most significant variations between variables to reveal the sometimes simple relationship among large sets of data (Owen 2014). It has been used by Biester et al. (2014) on peat samples after FTIR analysis to decipher underlying biogeochemical processes related either to decomposition and/ or changes in vegetation pattern. It can be used to analyse and discriminate samples that are of similar or different organic matter quality based on the peak heights at each wavelength. With prior knowledge of sample location and conditions conclusions can be derived regrding the underlying factors accounting for the differences. We therefore used PCA to make inferences regarding the processes and rates of decomposition occurring within the peat at various depths. The analysis was performed using Orange Software which is freely available at: https://orange.biolab.si/download/. 


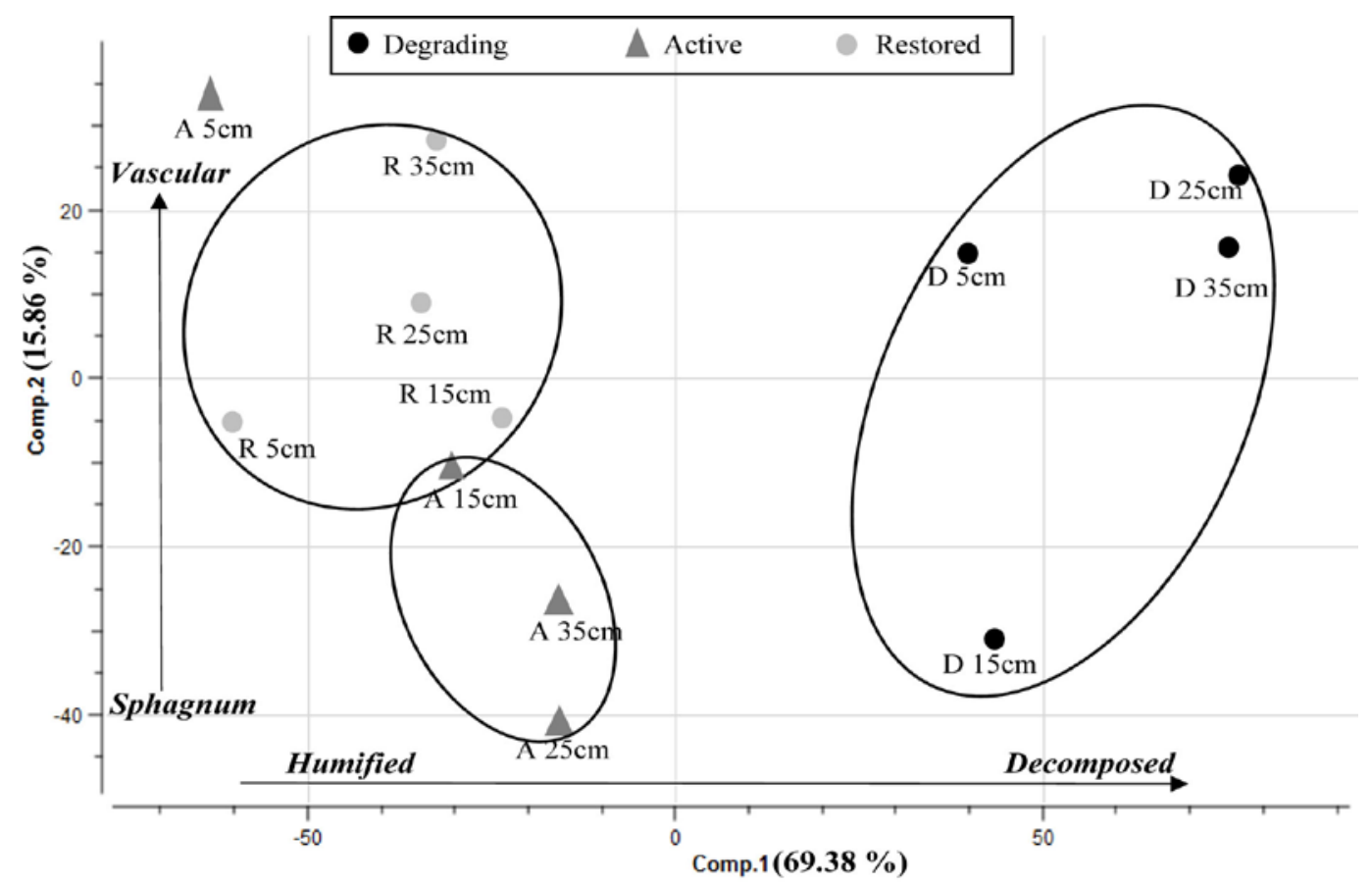

Fig. 4. PCA of average solid FTIR results (calculated from averaged raw data from Fig. 2) from each location at depths of $5,15,25$ and $35 \mathrm{cmbgl}$.

Fig. 4 displays the PCA analysis of the averaged absolute spectral values taken from Fig.2 from each of the three locations at various depths. In addition, PCA on the raw absolute (non-averaged) spectral values are shown in supplementary information 1 . The PCA's were created to easily visualize a generalized summary of the results, as it is difficult to differentiate trends using raw data. In Fig. 4 PC1 represents a significant proportion (69.38 \%) of the variance within the dataset and consequently shows a high level of variance between the active and restored locations compared to the degrading. The results for the active and the restored areas have negative values in the PC1 direction, whereas the degrading have positive values, indicating that the active and restored locations are of similar organic matter quality whereas the degrading location has a different organic composition. This would indicate that PC1 is driven by the organic signature which likely represents the degree of decomposition at each sample area, as during decomposition, labile organic compounds degrade first, corresponding to the humification ratio calculated in Fig. 3, which shows the degrading samples to be less humified/ more decomposed than both the active and restored locations. The significance of PC2 is more difficult to interpret as the significance is so low (15.86 \%). It is postulated that due to the negative loading of the samples from the active area, and also those from the surface of the restored area, PC2 may be driven by vegetation changes and that negatives values are associated with the occurrence of sphagnum. The positive values, specifically the deeper samples from the restored area (which may be representative of the organic 
matter composition of this area when it was previously under a degraded status, prior to drain blocking) and the majority of those from the degrading area correspond to a lower occurrence of sphagnum and vascular plant domination. This correlates with the condition and vegetation assessment undertaken by RSPB in conjunction with DAERA which determined the degrading area to be dominated by 'rush pasture and acid grassland, and thin peats with heath' and that the restored area contains 'a reduced coverage of sphagnum with heather and cotton grass present’ (information taken from table 1 pg. 6 (Burns 2011)).

\subsection{Stable Isotope Analysis}

Stable carbon and nitrogen isotopes are a widespread tool used to analyse biochemical processes in soils, based on the ratio of heavy to light isotopes. Isotopic fractionation occurs when decomposing bacteria preferentially use lighter isotopes during respiration which could lead to an enrichment of the heavier isotopes in the remaining organic material (Krüger et al. 2014). This kinetic fractionation means stable carbon and nitrogen analysis of solid peat samples with depth could therefore show a change in metabolic pathway from the acrotelm (aerobic) to the catotelm (anaerobic) and give an indication of rates of decomposition within the peat.

\subsubsection{Stable Isotope Analysis of ${ }^{13} \mathrm{C}$ and ${ }^{15} \mathrm{~N}$ and PCA in Solid Phase}

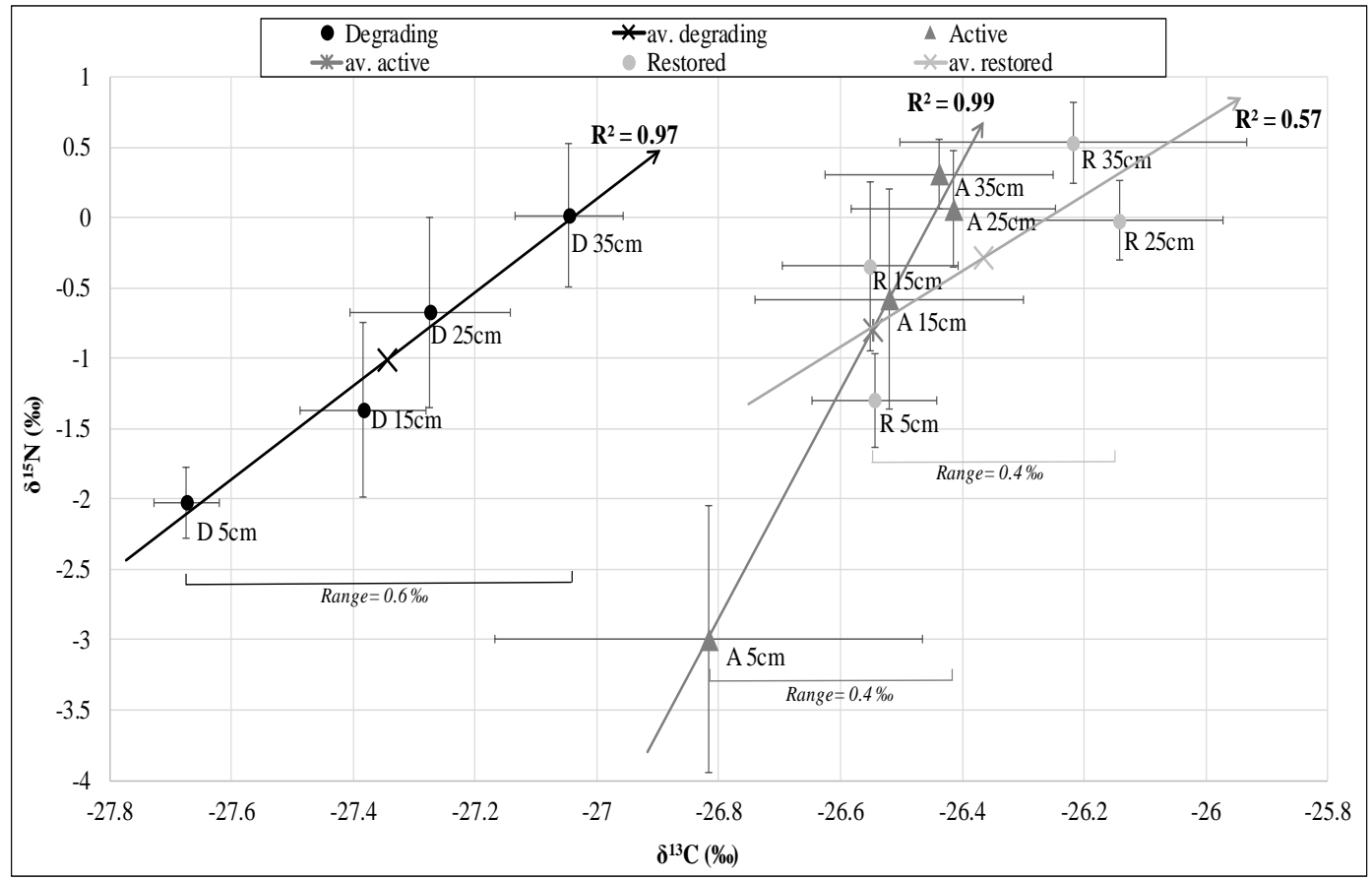


Fig. 5. Average ${ }^{13} \mathrm{C}$ and ${ }^{15} \mathrm{~N}$ values in the solid phase calculated from the 5 sample locations from the degrading (D), active (A) and restored (R) areas at depths of 5, 15, 25 and $35 \mathrm{~cm}$ (See Supplementary Information 2). Standard error was calculated and used for the addition of error bars

Average ${ }^{13} \mathrm{C}$ and ${ }^{15} \mathrm{~N}$ values (calculated from information shown in Supplementary Information 2) taken from each site at the various depths (Fig. 5) show that a clear depth trend can be seen at each location, especially in the case of the active $\left(\mathrm{R}^{2}=0.99\right)$ and the degrading $\left(\mathrm{R}^{2}=0.97\right)$ samples. The surface samples contain lower $\delta^{13} \mathrm{C}$ and $\delta^{15} \mathrm{~N}$ values which increase with depth. A uniform or only slightly increasing depth trend in the carbon isotopic signature is indicative of young/ poorly drained soils, whereas a pronounced $\delta^{13} \mathrm{C}$ increase with depth is typical of mature, well-drained soils, as decomposition favours the selective loss of ${ }^{12} \mathrm{C}$ (Alewell et al. 2011). This depth trend is shown in Fig. 5 as results show that both the active and restored samples have a smaller range $(0.4 \%)$ and more uniform depth trend than the degrading samples $(0.6 \%)$. Given that only the top $35 \mathrm{~cm}$ were sampled and given the trend line, this is expected to become more apparent with depth. In addition to this, the $\delta^{13} \mathrm{C}$ values associated with the active and restored samples have a distinct carbon isotopic shift (-26.82 to $26.15 \%$ ) compared with the degrading samples (-27.67 to $-27.04 \%$ ). This represents the ingression of vascular plants in the degrading area which produce more lignin rich litter, which tends to be depleted in ${ }^{13} \mathrm{C}$ (Gogo et al. 2012). This correlates with the aforementioned vegetation survey undertaken by RSPB in conjunction with DAERA (Burns 2011) that determined the degrading area to be the most dominated by rush pasture and acid grassland. 


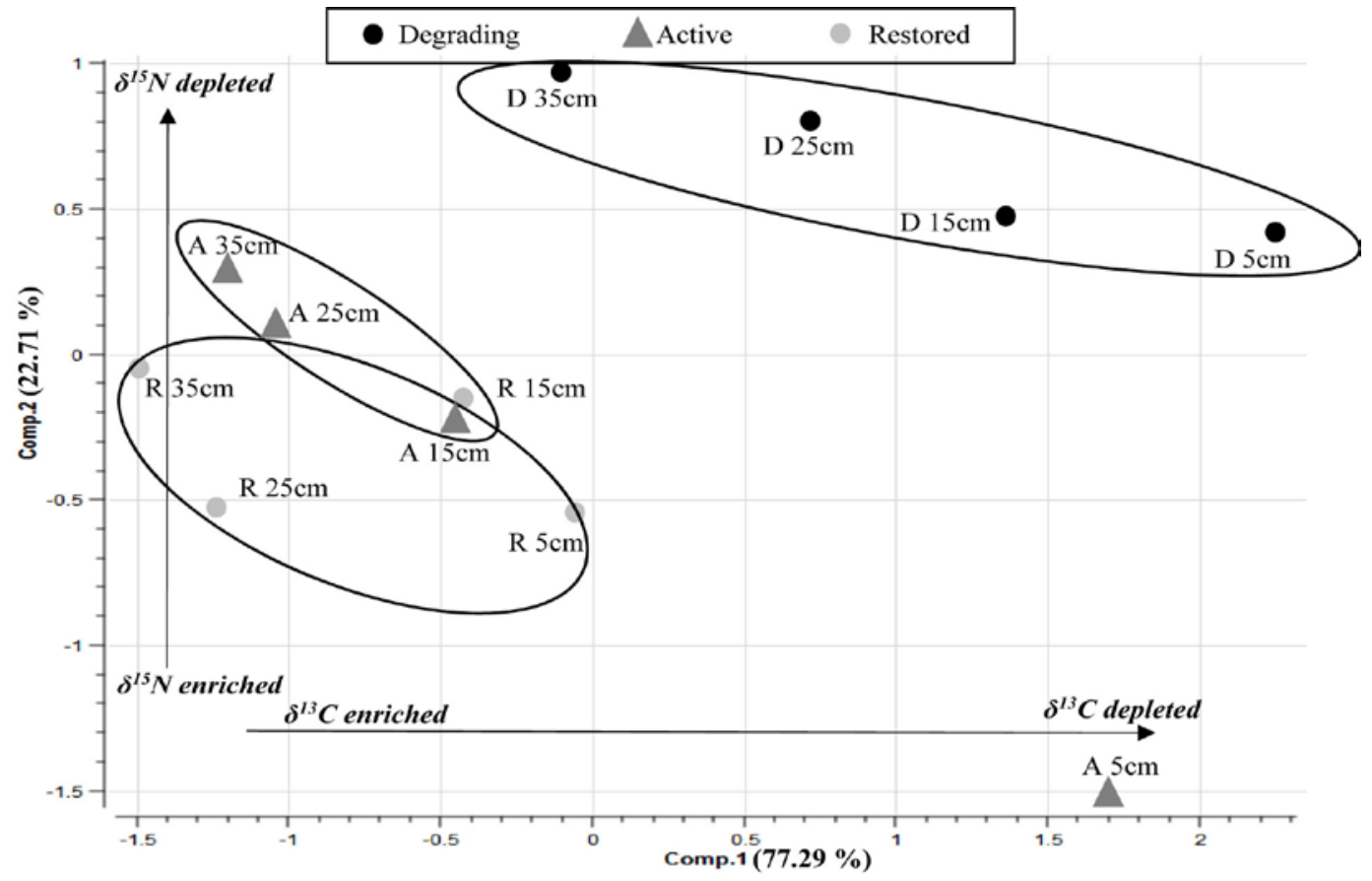

Fig. 6. PCA of average $\delta^{13} \mathrm{C}$ and $\delta^{15} \mathrm{~N}$ values in the solid phase (calculated from the data from Fig. 5) from each of the 5 sample locations at depths of 5, 15, 25 and $35 \mathrm{~cm}$

Fig. 6 illustrates the results achieved by PCA of the average $\delta^{13} \mathrm{C}$ and $\delta^{15} \mathrm{~N}$ values in the soil phase that are represented in Fig. 5. PC1 represents a significant proportion (77.29 \%) of the variance within the dataset and therefore shows a high level of variance between the active and restored locations, which cluster together and have negative values in the PC1 direction, compared to the degrading location, which have positive values. When comparing these results with those from Fig. 5 there is a clear correlation with PC1 being driven by the $\delta^{13} \mathrm{C}$ values and PC2 being driven by the $\delta^{15} \mathrm{~N}$ values. These results are very similar to those achieved from the PCA of FTIR data (Fig. 4). Which show that the organic composition and signature is closely related to the stable isotopic signature which are both affected and influenced by decomposition and vegetation legacy within the peat profile. It should also be noted that in both analyses, sample A $5 \mathrm{~cm}$ is an outlier, which was also the case in Figs. 4 and 5, indicating this is not an analytical or lab based error. When comparing this with data shown in supplementary information 2, this outlying result occurs due to the $\delta^{13} \mathrm{C}$ depleted samples taken from A1 and A4 at the surface ( $5 \mathrm{cmbgl})$. The occurrence of this result may be due to the effects of microtopography and that the water table may be lower at this location, causing an increase in aerobic decomposition at the surface or higher concentration of vascular plants compared to mosses, which correlates with the findings discussed in Fig. 4. This highlights the importance of a field sampling technique that takes several samples in order to be representative of the location in question. 


\subsubsection{Stable Isotope Analysis of ${ }^{18} \mathrm{O}$ and $\mathrm{D}$ in Liquid Phase}

Using the principle of kinetic fractionation, the stable isotopic signature of pore water can also be used as an indicator for the in situ distribution and activity of microbes in anoxic sediments, as during kinetic fractionation via decomposition and bacterial processes, methanogens preferentially remove the lighter hydrogen isotope $(1 \mathrm{H})$ from the surrounding pore water, causing an enrichment of the heavier isotope (deuterium (D)) (Siegel et al. 2001). In addition, during evaporation, the lighter oxygen $(16 \mathrm{O})$ and hydrogen $(1 \mathrm{H})$ isotopes are preferentially evaporated due to their higher vapour pressure (Stoll 2014). Craig (1961) established a correlation (eq. 2) between the depletion of the heavier oxygen isotope (180) and D in global freshwaters. He defined this interdependence as the 'Global Meteoric Water Line’ (GMWL) and is shown by the equation:

$$
\delta D=8 \delta^{18} O+10
$$

Equation (2) GMWL equation

This GMWL defines the relationship between $\delta 18 \mathrm{O}$ and $\delta \mathrm{D}$ in global freshwater, and takes into account tropical regions and areas of extreme climates. It was therefore preferential to use a Local Meteoric Water Line (LMWL) using precipitation data from a similar climate. Diefendorf \& Patterson (2005) collected monthly precipitation data from Ireland from 1957-2002 which was used to create a LMWL. Although this data was only collected in Valentia, in the southwest of Ireland, the data was chosen as it was readily available and collected over such a wide timescale. It is recognised however that this precipitation data may differ from the northeast of Ireland and may have elevation effects, however these are considered to have minimal impact on the results and are the best comparison available at this time. Comparing data collected at the Garron Plateau with this LMWL gives an indication of the rate of evaporation and storage of water within the peat. 


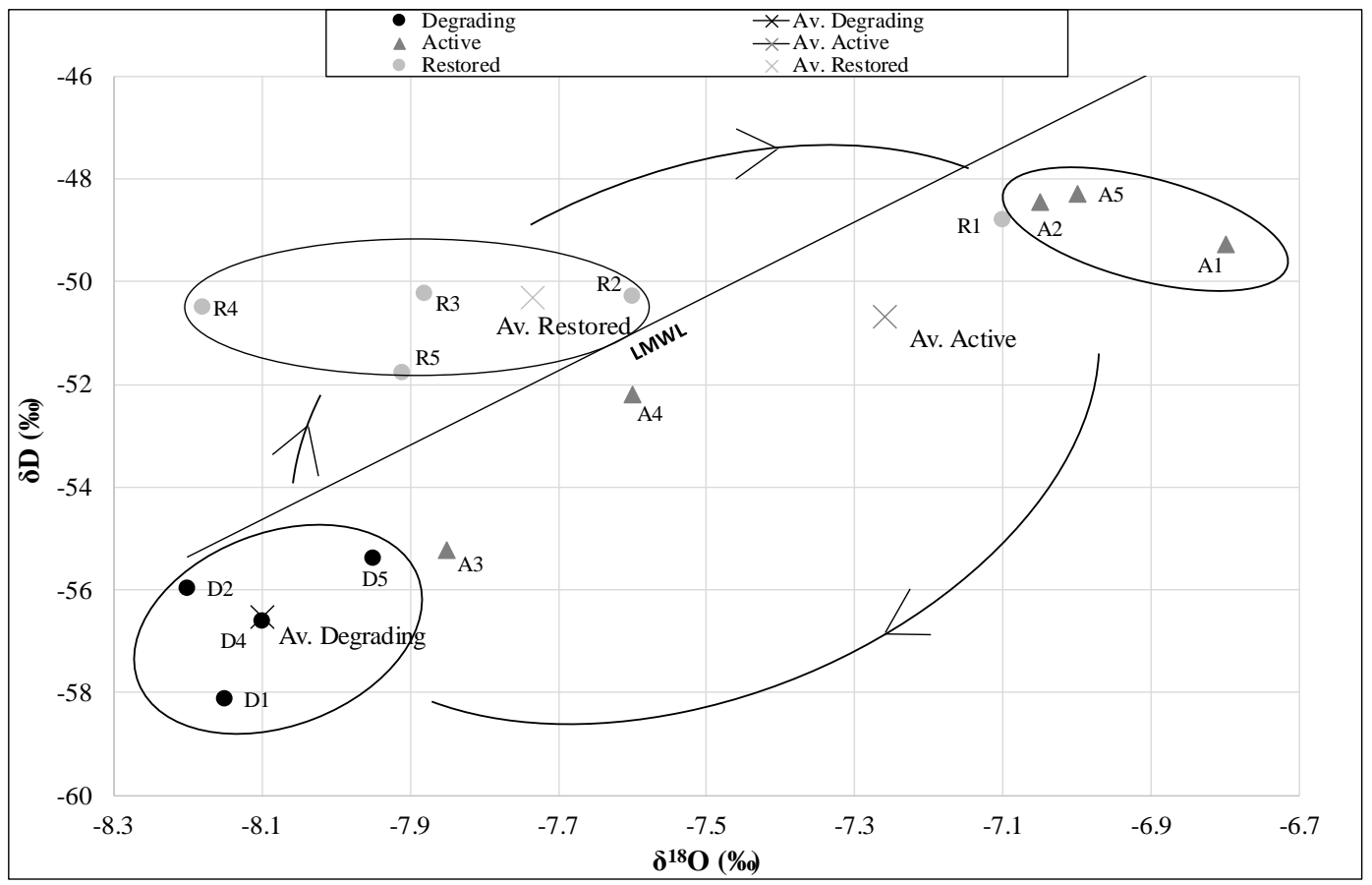

Fig. 7. Stable ${ }^{18} \mathrm{O}$ and D isotope analysis from pore water samples (N.B. D3 was dry so no water sample was obtained) compared with the LMWL

As indicated by Fig. 7, more positive (enriched) deuterium $(\delta \mathrm{D})$ values suggest that high rates of anaerobic microbial activity are occurring in the restored and active areas, as methanogens preferentially remove light $\left({ }^{1} \mathrm{H}\right)$ hydrogen from the surrounding interstitial pore fluids during the operation of their metabolic pathways (Siegel et al. 2001) causing an enrichment of the heavier isotope. Samples A3 and A4 have slightly depleted $\delta \mathrm{D}$ values, which may be a result of drier conditions here as a result of micro topographical differences, causing a depletion in methanogenic activity. However, when comparing the $\delta^{18} \mathrm{O}$ values with the LMWL from precipitation data collected in Valentia, all of the samples (including A3 and A4) from both the degrading and active samples are more enriched in $\delta^{18} \mathrm{O}$, indicating higher rates of evaporation when compared to rainfall data from Valentia. This occurs as lighter isotopes $\left({ }^{18} \mathrm{O}\right)$ are preferentially evaporated due to their higher vapour pressure, causing an enrichment in the remaining water (Stoll 2014). Although in general, samples from the same area cluster together, samples A3 and A4 fall out of this clustering, however, most importantly, are still are enriched in $\delta^{18} \mathrm{O}$ relative to the LMWL, as are all of the active and degrading samples. This enrichment indicates high levels of evaporation (Stoll 2014), and suggests that water movement in these areas and therefore water table fluctuation is limited. The samples from the restored area are depleted in $\delta^{18} \mathrm{O}$ (with the exception of R1) when compared to the LMWL, indicating lower rates of evaporation and greater transport of water, as continuous influx of water is 
expected to depress the level of ${ }^{18} \mathrm{O}$ enrichment in an open pool (Keimowitz et al. 2013). Sample R1 suggests that this location has a higher rate of evaporation, similar to that of the active and degrading locations, which may be due to this sample being located closest to a blocked drain, possibly holding the water in place more easily than the other sample locations.

\subsubsection{Stable Isotope Analysis of ${ }^{13} \mathrm{C}$ and ${ }^{18} \mathrm{O}$ in Soil Gas Phase}

In addition to the stable isotopic signature of solid and liquid material, stable carbon and oxygen isotope analysis of gases being released from the peat is also a useful indicator of decomposition processes via fractionation between the solid and gas phases.

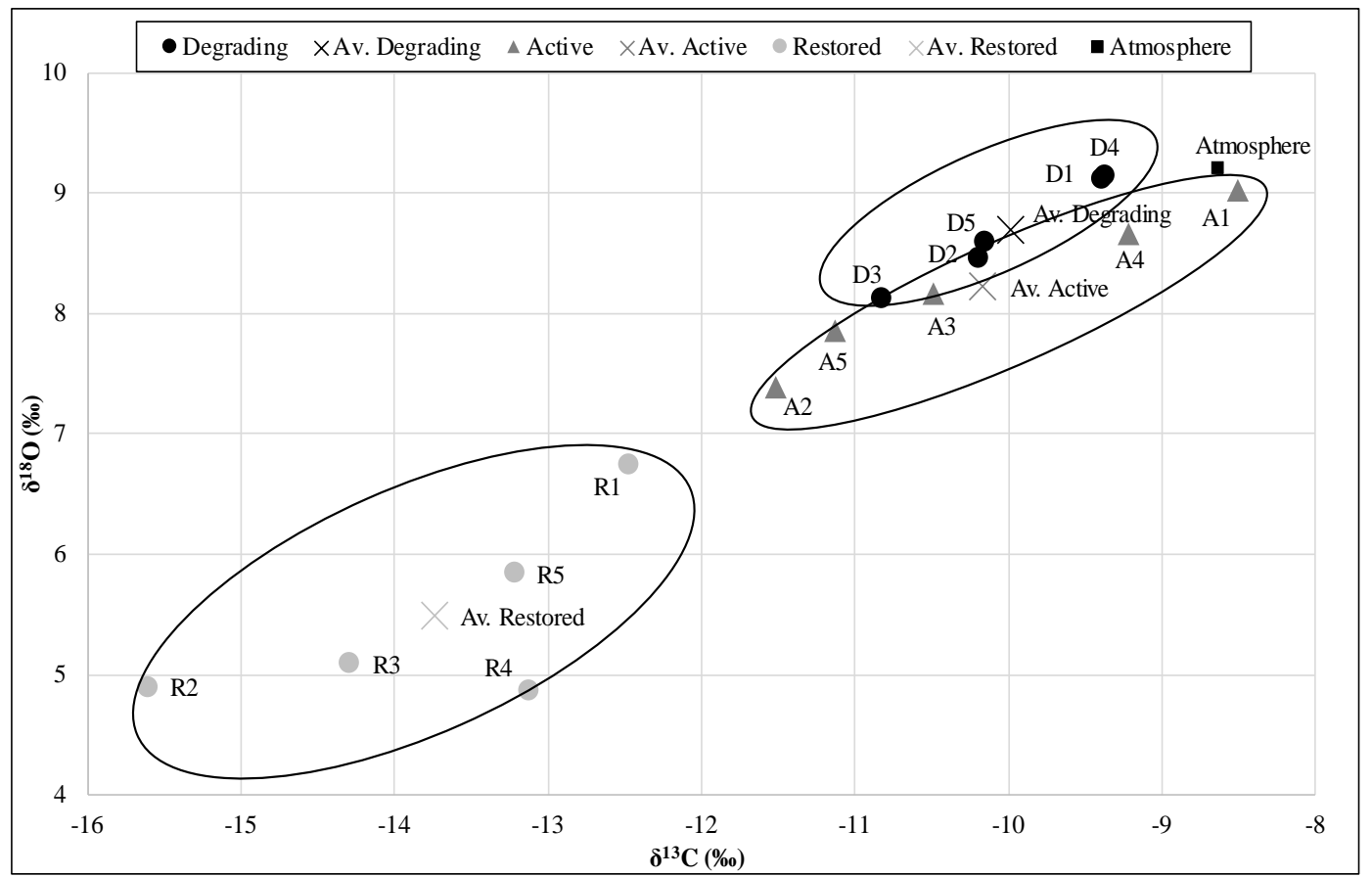

Fig. 8. Stable ${ }^{13} \mathrm{C}$ and ${ }^{18} \mathrm{O}$ isotope analysis of carbon dioxide in soil gas samples taken from the 5 sample locations within the degrading (D), active (A) and restored (R) areas. An atmospheric sample from the Garron Plateau is also shown.

Fig. 8 shows that the results from each area (with the exception of A1) have lower $\delta^{13} \mathrm{C}$ and $\delta^{18} \mathrm{O}$ values relative to the atmospheric (aerobic) result. The results for the degrading area are the most similar to the results from the aerobic conditions. The samples collected from the restored area have the lowest $\delta^{13} \mathrm{C}$ and $\delta^{18} \mathrm{O}$ values, this is as expected as when compared to the $\delta^{13} \mathrm{C}$ values in the solid phase (Fig. 5), the restored samples are the most 
enriched, indicating high levels of fractionation in the solid phase, leading to depletion of $\delta^{13} \mathrm{C}$ in the gas phase. The opposite occurs with regards to the degrading samples, whereby the $\delta^{13} \mathrm{C}$ values are depleted in the soil phase and enriched in the gas phase. Unexpectedly, the active area lies between the two, being relatively more enriched in the solid phase and slightly also slightly enriched in the gas phase. However when comparing this with the $\delta^{13} \mathrm{C}$ results from Fig. 5, the active location also lies central between the degrading and restored values. In addition, in both Figs. 5 and 6, sample A $5 \mathrm{~cm}$ has been an outlier. When comparing these results with the absolute $\delta^{13} \mathrm{C}$ and $\delta^{15} \mathrm{~N}$ values in the soil phase, (see supplementary information 2) this depletion can be attributed to sample A1, which is greatly depleted at both 5 and $15 \mathrm{cmbgl}$. This depletion in the solid phase accounts for the relative enrichment in the gas phase, seen in Fig. 8. As previously mentioned, this is expected to be a result of microtopography, where the water table may be lower than the other active locations, causing increased aerobic decomposition and a dominance of vascular plants due to the drier conditions. When comparing the $\delta^{18} \mathrm{O}$ values between the liquid (Fig. 7) and gas phases, the degrading samples are enriched in $\delta^{18} \mathrm{O}$ in the gas phase and depleted in the liquid phase. The opposite again occurs with the restored samples, whereby the $\delta^{18} \mathrm{O}$ values are depleted in the gas phase and enriched in the liquid phase. Similar to comparing the $\delta^{13} \mathrm{C}$ fractionation between the solid and gas phases, the $\delta^{18} \mathrm{O}$ values from the active area are generally in between extremities, being slightly enriched in both the gas phase and liquid phase. The level of the water table is known to be an important control of $\mathrm{CO}_{2}$ production in peatlands, however it's influence is highly complex and intricate. Estop-aragonés \& Blodau (2012) and Hogg et al. (1992) have found that compared to water saturated conditions, $\mathrm{CO}_{2}$ production typically increases with drying only up until an optimum moisture content and then decreases upon further drying. They found that this response differs greatly between sites and also with depth within a given site, highlighting the intricacy with which conceptual models need to be created. 
3.2.4. PCA of Stable Isotope Analysis in Solid, Liquid and Gas Phases.
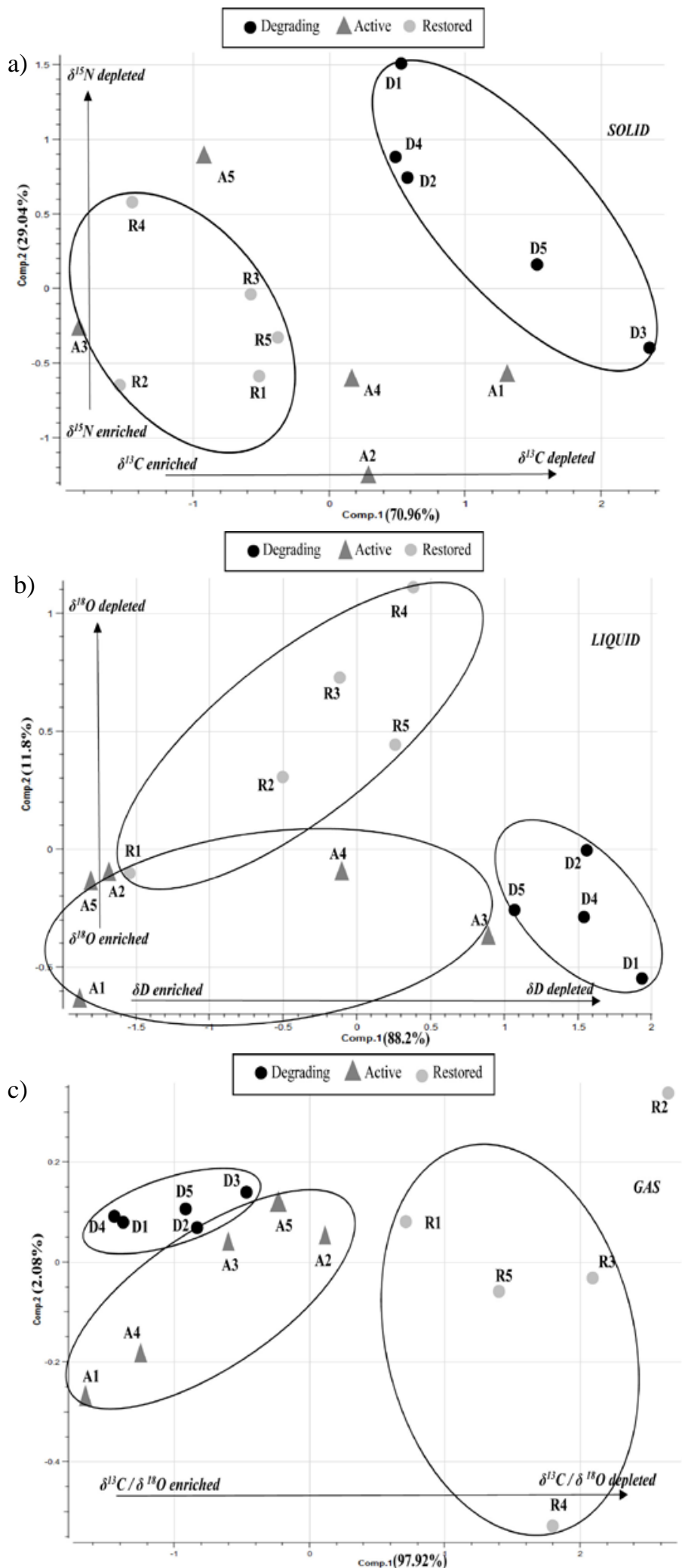

Fig. 9. PCA of average $\delta^{13} \mathrm{C}$ and $\delta^{15} \mathrm{~N}$ values in the solid phase (calculated from data from supplementary information 2$)(\mathbf{a}), \delta^{18} \mathrm{O}$ and $\delta \mathrm{D}$ values in the liquid phase (calculated from data from Fig. 7) (b) and $\delta^{13} \mathrm{C}$ and $\delta^{18} \mathrm{O}$ in the gas phase (calculated from data from Fig. 8) (c). 
Fig. 9 illustrates the PCA of the isotopic analysis taken in solid (a), liquid (b) and gas (c) phases. The results indicate that in each case there is high loading associated with the first component $(>70 \%)$. When compared to Figs. 4-6, the results suggest that more negative values in the PC1 direction indicate isotopically depleted values, whereas more positive values indicate isotopic enrichment. In particular, Fig. 9a suggests that the main driver for PC1 may be the $\delta^{13} \mathrm{C}$ values and PC2 the $\delta^{15} \mathrm{~N}$ values when compared to the results from Fig. 5. When comparing Fig. $9 \mathrm{~b}$ with the liquid phase values from Fig. 7 it is supposed that PC1 is driven by $\delta \mathrm{D}$ values, and PC2 by the $\delta 180$ values as the same trends are shown in both cases. In addition, comparing the PCA of Fig. 9c with the gas results from Fig. 8 suggest that PC1 may be driven by either $\delta^{13} \mathrm{C}$ or $\delta^{18} \mathrm{O}$ values, given that the PC2 loading is very minimal (2.08 \%). When comparing each area between phases, for example the restored area, Fig. 9 suggests that this area becomes gradually depleted moving from solid, to liquid to gas phases, indication high levels of fraction. The samples from the active area are generally centralized, indicating low rates of fractionation, but becoming slightly more enriched moving from solid, liquid and gas phases. The results from the degrading area indicate minimal fractionation from the solid to liquid phase, but dramatic fractionation between either the solid to gas or liquid to gas phase.

\section{Conceptual Understanding of System}

Peatlands are not only complex but delicate systems whereby drainage and degradation can happen on a rapid scale. Prior to modern protection and restoration policies, a diplotelmic model of general peat structure was created by Ingram (1978), which characterizes peatlands as consisting of an acrotelm and catotelm. This has been commonly accepted as peatland structure (Evans et al. (1999); Slater et al. (2007); Rosa \& Larocque (2008)), however we propose that this may not be valid for all peatlands. Our results support the postulation by Ingram (1978) that humification does increase moving from the acrotelm to the deeper catotelm. However in both the active and degrading sites at the Garron Plateau there is a zone of intense decomposition in the subsurface. This zone was also found between the acrotelm and catotelm on raised bog cores from Sweden (Franzén 2006) and in the Jura mountains in Switzerland (Cocozza et al. 2003) indicating that it is not limited to blanket bog sites. This zone was defined by Clymo \& Bryant (2008) as the ‘mesotelm’ which is usually anoxic, but periodically oxic. This zone of intense decomposition occurs as microorganisms are most active at redox boundaries where they can benefit from access to various reductants and oxidants generated during redox 
cycling events (Hines 2006). At the Garron Plateau stable isotopic analysis of ${ }^{18} \mathrm{O}$ indicated that both the active and degrading areas, are enriched in $\delta^{18} \mathrm{O}$ relative to the LMWL, indicating high levels of evaporation (Stoll 2014), which would suggest that water movement in these areas and therefore water table fluctuation is limited. The restored area was depleted in $\delta^{18} \mathrm{O}$ relative to the LMWL, indicating low levels of evaporation and high rates of water table fluctuation and consequently contains no evident zone of increased decomposition, and no clear redox boundary. This may be due to drying and subsequent rewetting of the peat as part of the restoration, which has caused the enhancement of physical fractures resulting in a secondary porosity that promotes greater transmissivity of water.

In addition, stable isotopic analysis of the solid, liquid and gas phases has shown that the active location is enriched in all phases, which indicates that this area has the lowest rates of fractionation between phases, suggesting a stabilized, enclosed system. Actively accumulating peatlands are stable systems when methane production is balanced by methane consumption. Segers (1998) proposed that a large and varying part (1-90\%) of the produced methane could be consumed again by methane oxidizing bacteria present in the oxic top layer or in the oxic rhizosphere. Smemo and Yavitt (2006 and 2007) also found that anaerobic oxidation of methane occurs simultaneously with methanogenesis and can consume significant amounts of gross $\mathrm{CH}_{4}$, constraining atmospheric $\mathrm{CH}_{4}$ flux under certain conditions. This highlights the complexity of the multiple factors at play even in active peatland areas.

As the peat degrades, both the solid $\left(\delta^{13} \mathrm{C}\right.$ and $\left.\delta^{15} \mathrm{~N}\right)$ and liquid $(\delta \mathrm{D})$ phases are depleted whereas the gas $\left(\delta^{13} \mathrm{C}\right.$ and $\left.\delta^{18} \mathrm{O}\right)$ phase remains enriched. This indicates increased decomposition, as aerobic decomposition results in relatively lighter $\delta^{13} \mathrm{C}$ values which increase with depth (Alewell et al. 2011), causing an enrichment in the gas phase and depletion of $\delta \mathrm{D}$ in the liquid phase due to increased aerobic decomposition and decreased anaerobic microbial activity. In addition, the depleted $\delta^{13} \mathrm{C}$ values associated with the solid phase may be reflective of vegetation changes in the degrading location, as vascular plants, composed of lignin tend to be depleted in ${ }^{13} \mathrm{C}$ (Gogo et al. 2012). Fernandez (2003) also found a consistent trend whereby enrichment in the gas phase was concurrent with depletion of residual carbon in the solid phase as a result of ongoing decomposition.

The results from the restored location indicate enrichment of $\delta^{13} \mathrm{C}$ and $\delta^{15} \mathrm{~N}$ in the solid phase and enrichment of $\delta \mathrm{D}$ in the liquid phase. Raising the water table and rewetting the peat has increased microbial activity, enriched $\delta \mathrm{D}$ in the liquid phase, with $\delta^{13} \mathrm{C}$ and $\delta^{15} \mathrm{~N}$ more enriched in the solid phase, this fractionation 
subsequently causes isotopic depletion in the gas phase, as microbes preferentially respire ${ }^{12} \mathrm{C}$ (Yang et al. 2014) causing depletion of $\delta^{13} \mathrm{C}$ in the gas phase. This may be due to the high water table fluctuation which causes the peat system to become less stable and open, as gases produced by microbial activity are not consumed within the system. This is similar to the mechanism suggested by Fenner \& Freeman (2011) where rewetting of peats can cause accelerated carbon losses to the atmosphere. It is also possible that this gas fractionation signal may be 'non unique', suggesting that complex microbial mediated reactions between $\mathrm{CO}_{2}, \mathrm{CH}_{4}$ and other volatile compounds such as isoprene (Galand et al. 2010). Isoprene accounts for approximately one third of the total flux of volatile organic compounds to the atmosphere, an amount similar to methane (Cleveland \& Yavitt 1998) yet has not been extensively studied in peatlands.

The isotopic analysis at each location has shown that the process of fractionation is quite systematic and that the process of degradation or restoration is somewhat cyclic. Using the results obtained from this project a site-specific model for the processes occurring at the Garron Plateau has been put forward: 


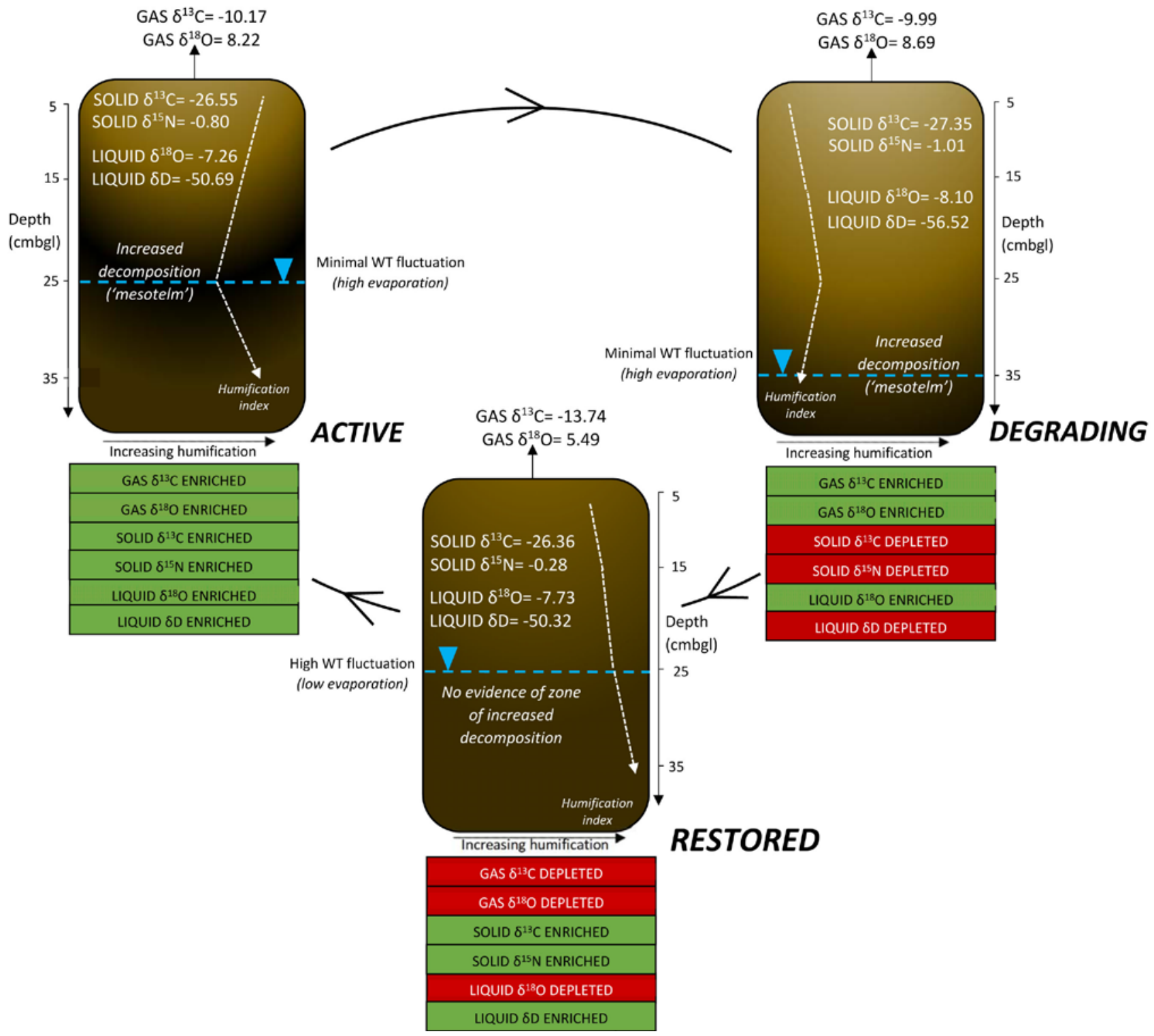

Fig. 10. Proposed conceptual model of isotopic fractionation and humification processes at the Garron Plateau

\section{Conclusions}

This proposed conceptual model of active, degrading and restored peatlands summarises the increasing rate of humification with depth at each location, and the subsurface zones of increased decomposition in both the active and degrading areas, which combined with stable isotopic analysis, is postulated to be due to a stable water table 
and redox boundary. This zone is not evidenced in the restored location which may be a result of a fluctuating water table which may result in isotopically depleted gas. It is evident that restoration of drained or overgrazed peatlands rewetting does result in some reversal of degradation mechanisms producing similar outputs to an actively accumulating peatland (increased humification), which can be easily monitored using chemical and stable isotopic methods. However, there are still mechanisms around fluctuation of the restored water table and the resulting generation of soil gases that need to be understood if such restoration is to be seen as effective.

\section{Future Research}

These results achieved from this project indicate that following a multi-analytical approach (stable isotopic analysis and organic chemistry) is required to fully assess and understand the complex processes that occur in peatlands. Future work related to this project would entail the use of metagenomic analysis to determine how microbial communities functionally interact in the degradation of peatlands and how they respond to environmental changes such as drainage and re-wetting.

\section{Acknowledgements}

This research was funded by the Department of Employment and Learning (DEL). Rory Doherty was supported by the REMEDIATE (Improved decision-making in contaminated land site investigation and risk assessment) Marie-Curie Innovation Training Network. Thermo Scientific (H.J. Jost) are thanked for providing the Delta Ray Isotope Ratio Infrared Spectrometer which was used for gas phase stable isotopic analysis. Roy Taylor of Northern Ireland Water is also thanked for granting access to and providing permission for sampling at the Garron Plateau. 


\section{References}

Alewell, C. et al., 2011. Stable carbon isotopes as indicators for environmental change in palsa peats. Biogeosciences, 8, pp.1769-1778.

Artz, R.R.E. et al., 2008. FTIR spectroscopy can be used as a screening tool for organic matter quality in regenerating cutover peatlands. Soil Biology and Biochemistry, 40(2), pp.515-527.

Biester, H. et al., 2014. Comparison of different methods to determine the degree of peat decomposition in peat bogs. Biogeosciences, 11(10), pp.2691-2707.

Biester, H. et al., 2005. Halogens in porewater of peat bogs - the role of peat decomposition and dissolved organic matter. Biogeosciences Discussions, 2(5), pp.1457-1486.

Boelter, D.H., 1966. Important Physical Properties of Peat Materials. Proceedings, third international peat congress, (Bay), pp.150-154. Available at: http://www.treesearch.fs.fed.us/pubs/12921.

Bonnett, S. et al., 2009. A review of techniques for monitoring the success of peatland restoration. University of Liverpool., (Natural Englan Commissioned Reports, Number 086). Available at: http://eprints.uwe.ac.uk/21937/.

Burns, S., 2011. Dungonnell Reservoir Catchment Management Plan: Rebuilding the Countryside. Internal Report. (Unpublished).

Cleveland, C.C. \& Yavitt, J.B., 1998. Microbial Consumption of Atmospheric Isoprene in a Temperate Forest Soil. Applied and environmental microbiology, 64(1), pp.172-177.

Clymo, R.S., 2015. Why are there few gas bubbles in deep peat in British raised and blanket peat bogs ? Mires and peat, 16(5), pp.1-20.

Clymo, R.S. \& Bryant, C.L., 2008. Diffusion and mass flow of dissolved carbon dioxide, methane, and dissolved organic carbon in a 7-m deep raised peat bog. Geochimica et Cosmochimica Acta, 72(8), pp.2048-2066. Available at: http://www.sciencedirect.com/science/article/pii/S0016703708000835.

Cocozza, C. et al., 2003. Characterization of solid and aqueous phases of a peat bog profile using molecular fluorescence spectroscopy, ESR and FT-IR, and comparison with physical properties. Organic Geochemistry, 34, pp.49-60.

Committee on Climate Change, 2013. Chapter 4: Regulating Services - upland peat, Available at: http://www.theccc.org.uk/wp-content/uploads/2013/07/ASC-2013-Chap4_singles_2.pdf. 
Department of the Environment for Northern Ireland, 2003. Northern Ireland Habitat Action Plan Blanket Bog, Belfast.

Esmeijer-Liu, A.J. et al., 2012. Stable Carbon and Nitrogen Isotopes in a Peat Profile Are Influenced by Early Stage Diagenesis and Changes in Atmospheric $\mathrm{CO}(2)$ and N Deposition. Water, air, and soil pollution, 223(5), pp.2007-2022.

Available

at: http://www.pubmedcentral.nih.gov/articlerender.fcgi?artid=3359457\&tool=pmcentrez\&rendertype=abstra ct [Accessed January 5, 2015].

Estop-aragonés, C. \& Blodau, C., 2012. Soil Biology \& Biochemistry Effects of experimental drying intensity and duration on respiration and methane production recovery in fen peat incubations. Soil Biology and Biochemistry, 47, pp.1-9. Available at: http://dx.doi.org/10.1016/j.soilbio.2011.12.008.

Estop-Aragonés, C., Knorr, K.H. \& Blodau, C., 2013. Belowground in situ redox dynamics and methanogenesis recovery in a degraded fen during dry-wet cycles and flooding. Biogeosciences, 10, pp.421-436.

Evans, M.G. et al., 1999. Runoff generation and water table fluctuations in blanket peat: Evidence from UK data spanning the dry summer of 1995. Journal of Hydrology, 221(3-4), pp.141-160.

Fenner, N. \& Freeman, C., 2011. Drought-induced carbon loss in peatlands. Nature Geoscience, 4(12), pp.895900. Available at: http://www.nature.com/doifinder/10.1038/ngeo1323 [Accessed May 30, 2013].

Fernandez, I., 2003. Carbon isotopic fractionation during decomposition of plant materials of different quality. Global Biogeochemical Cycles, 17(3), pp.1-12.

Franzén, L.G., 2006. Increased decomposition of subsurface peat in Swedish raised bogs: are temperate peatlands still net sinks of carbon? Mires and Peat, 1 (3) pp.1-16.

Galand, P.E., Yrjälä, K. \& Conrad, R., 2010. Stable carbon isotope fractionation during methanogenesis in three boreal peatland ecosystems. Biogeosciences, 7, pp.3893-3900. Available at: www.biogeosciences.net/7/3893/2010/ [Accessed March 1, 2017].

van Geldern, R. \& Barth, J.A.C., 2012. Optimization of instrument setup and post-run corrections for oxygen and hydrogen stable isotope measurements of water by isotope ratio infrared spectroscopy (IRIS). Limnology and Oceanography: Methods, 10(1999), pp.1024-1036. Available at: http://www.aslo.org/lomethods/free/2012/1024.html.

Gogo, S. et al., 2012. Spatial and temporal variations of dissolved organic carbon and inorganic carbon concentrations and $\delta 13 \mathrm{C}$ in a peatland-stream continuum: implications of peatland invasion by vascular plants. Biogeosciences Discussions, 9(3), pp.3515-3544. Available at: http://www.biogeosciences- 
discuss.net/9/3515/2012/ [Accessed March 1, 2017].

Grube, M. et al., 2006. Evaluation of sewage sludge-based compost by FTIR spectroscopy. Geoderma, 130(34), pp.324-333.

Harrison, B. et al., 2006. Differentiation of peats used in the preparation of malt for Scotch whisky production using Fourier transform infrared spectroscopy. Journal of the Institute of Brewing, 112, pp.333-339. Available at: http://onlinelibrary.wiley.com/doi/10.1002/j.2050-0416.2006.tb00739.x/abstract.

Hines, M.E., 2006. Microbially Mediated Redox Cycling at the Oxic-Anoxic Boundary in Sediments: Comparison of Animal and Plant Habitats. In The Interactions Between Sediments and Water. Dordrecht, The Netherlands: Springer Netherlands, pp. 159-172.

Hoefs, J., 2009. Isotope Fractionation Processes of Selected Elements. Stable Isotope Geochemistry, pp.35-92.

Hogg, E., Lieffers, V.J. \& Wein, R.W., 1992. Potential Carbon Losses From Peat Profiles: Effects of Temperature , Drought Cycles , and Fire. Ecological Society of America, 2(3), pp.298-306.

Holmgren, A. \& Norden, B., 1988. Characterization of Peat Samples By Diffuse Reflectance Ft-Ir Spectroscopy. Applied Spectroscopy, 42(2), pp.255-262.

Ingram, H.A.P., 1978. Soil layers in mires: function and terminology. Soil Sci, 29, pp.224-227.

Johnson, C.C., 2005. 2005 G-BASE Field Procedures Manual. British Geological Survey Internal Report, IR/05/097, Available at: http://nora.nerc.ac.uk/5190/1/2005proceduresmanual.pdf.

Keimowitz, A.R. et al., 2013. Identification of Ombrotrophic Bogs in the Catskill Mountains , NY by Geochemical and Isotopic Methods. Wetlands, 33, pp.355-364.

Krüger, J.P., Leifeld, J. \& Alewell, C., 2014. Degradation changes stable carbon isotope depth profiles in palsa peatlands. $\quad$ Biogeosciences, $11(12), \quad$ pp.3369-3380. Available http://www.biogeosciences.net/11/3369/2014/ [Accessed December 9, 2014].

Lai, D.Y.F., 2009. Methane Dynamics in Northern Peatlands: A Review. Pedosphere, 19(4), pp.409-421. Available at: http://dx.doi.org/10.1016/S1002-0160(09)00003-4.

McKeown, R. \& Corbett, P., 2015. Garron Plateau SAC Conservation Objectives,

Morris, P.J. et al., 2011. Conceptual frameworks in peatland ecohydrology: Looking beyond the two-layered ( acrotelm - catotelm ) model. Ecohydrology, 4.

Niemeyer, J., Chen, Y. \& Bollag, J.., 1992. Characterization of Humic Acids, Composts and Peat by Diffuse Reflectance Fourier-Transform Infrared Spectroscopy. Soil Science Society of America, 56(1), pp.135140. 
Owen, J., 2014. Principal Component Analysis: Data Reduction and Simplification. McNair Scholoars Research Journal, 1(2).

Parish, F. et al., 2008. Assessment on Peatlands, Biodiversity and Climate Change: Main Report. Global Environment Centre, Kuala Lumpur and Wetlands International, Wageningen.

Peltre, C. et al., 2014. Assessing soil constituents and labile soil organic carbon by mid-infrared photoacoustic spectroscopy. Soil Biology and Biochemistry, 77, pp.41-50.

Rosa, E. \& Larocque, M., 2008. Investigating peat hydrological properties using field and laboratory methods: application to the Lanoraie peatland complex (southern Quebec, Canada). Hydrological Processes, 22, pp.1866-1875. Available at: http://jamsb.austms.org.au/courses/CSC2408/semester3/resources/ldp/absguide.pdf.

Segers, R., 1998. Methane production and methane consumption : a review of processes underlying wetland methane fluxes. Biogeochemistry, 41, pp.23-51.

Shi, X. et al., 2015. Representing northern peatland microtopography and hydrology within the Community Land Model. Biogeosciences, 12(21), pp.6463-6477.

Siegel, D.I. et al., 2001. Estimating methane production rates in bogs and landfills by deuterium enrichment of pore water. Atomic Energy, 15(4), pp.967-975.

Slater, L. et al., 2007. Resistivity-based monitoring of biogenic gases in peat soils. Water Resources Research, 43(10), pp.1-13.

Smemo, K.A. \& Yavitt, J.B., 2006. A Multi-year perspectivve on methane cycling in a shallow peat fen in central New York State, USA. Wetlands, 26(1), pp.20-29.

Smemo, K.A. \& Yavitt, J.B., 2007. Evidence for Anaerobic CH 4 Oxidation in Freshwater Peatlands. Geomicrobiology Journal, 24, pp.583-597.

Stoll, M., 2014. $H$ and $O$ stable isotope compositions of different soil water types - effect of soil properties. Swedish University of Agricultural Sciences. Avaliable at: http://stud.epsilon.slu.se.

Tinch, R., 2009. Assessing Socio-economic Benefits of Natura 2000 - a Case Study on the ecosystem service provided by the Sustainable Catchment Management Programme. Output of the project Financing Natura 2000: cost estimate and benefits of Natura 2000., p.28pp.

Walter, J. et al., 2015. Multi-scale analysis of electrical conductivity of peatlands. European Journal of Soil Science, 66(July), pp.639-650.

Wynn, J.G., Bird, M.I. \& Wong, V.N.L., 2005. Rayleigh distillation and the depth profile of 13 C / 12 C ratios 
of soil organic carbon from soils of disparate texture in Iron Range National Park , Far North Queensland , Australia. Geochimica et Cosmochimica Acta, 69(8), pp.1961-1973.

Yakushev, E. V \& Newton, A., 2013. Chemical Structure of Pelagic Redox Interfaces: Observation and Modelling.,

Yang, W. et al., 2014. Biological 12C-13C fractionation increases with increasing community-complexity in soil microcosms. Soil Biology and Biochemistry, 69, pp.197-201. Available at: http://dx.doi.org/10.1016/j.soilbio.2013.10.030.

Zeebe, R.E. \& Wolf-Gladrow, D., 2001. Stable Isotope Fractionation. CO2 in Seawater: Equilibrium, Kinetics, Isotopes, pp.141-250.

Zerva, A., 2004. Comparison of closed static and dynamic chamber methods for the measurement of soil CO 2 efflux. Edinburgh University Thesis, 2, p.190. 